\title{
Susceptibility of Bryobia cristata (Acari: Tetranychidae) adults to infection by Metarhizium anisopliae and Beauveria bassiana
}

\author{
Maha S. Nada*; M. H. A. Mahgoub and Reham I. A. Abo-Shnaf \\ Plant Protec. Res. Institute, Agric. Res. Center, Dokki, Giza, Egypt \\ *Corresponding author: mahasalah2@Gmail.com
}

\begin{abstract}
Laboratory bioassay of the two entomopathogenic fungi Metarhizium anisopliae (Metschnikoff) Sorokin and Beauveria bassiana (Balsamo) Vuillemin (Ascomycota : Hypocreales) against Bryobia cristata (Dugès) (Acari: Tetranychidae) adults was evaluated. $M$. anisopliae had higher activity and rapid mortality against mite adults. The correspondent $\mathrm{LC}_{50}$ for $M$. anisopliae and $B$. bassiana was $1.82 \times 10^{6}$ and $2.98 \times 10^{6}$ spores $/ \mathrm{ml}$, respectively. The $\mathrm{LT}_{50}$ at dosage $10^{8}$ spores $/ \mathrm{ml}$ of $M$. anisopliae and $B$. bassiana was 2.2 and 4.08 days, respectively.
\end{abstract}

Key Words: Bryobia cristata, Entomopathogenic fungi, Metarhizium anisopliae, Beauveria bassiana, bioassays.

\section{INTRODUCTION}

Bryobia cristata (Tetranychidae) is a plant feeder with a long list of known hosts. This list includes legumes (such as alfalfa, peas, and clovers), various weed species found in lawns, lawn grasses, vegetables, fruit trees (e.g., plume, apple, orcherry trees), certain ornamental plant shrubs and trees. $B$. cristata was recorded in Egypt on wormseed grass Chenopodium ambrosioides L. at Dakahlia Governorate (Zaher 1984). The wide use of acaricides caused many problem's such as environmental pollution, distruction in the natural balance between the pest and natural enemy. Fungal pathogens as biocontrol agents now are accepted and have become important as one of the biological control components in the IPM programs (Nugroho and Bin Ibrahim 2004). Entomopathogenic fungi like Beauveria bassiana (Balsamo) Vuillemin and Metarhizium anisopliae (Metschnikoff) Sorokin (Ascomycota: Hypocreales) are density-dependent mortality factors in susceptible host populations and successful infection depends on the host receiving a threshold of infective conidia (Vandenburg et al., 1998; Hughes et al., 2004). This study was conducted to investigate the potential importance of the two entomopathogenic fungi $B$. bassiana and $M$. anisopliae against $B$. cristata adults.

\section{MATERIALS AND METHODS}

\section{Experimental mite cultures}

$B$. cristata was collected from infested malva plants (Malva sylvestris) from the Faculty of Agriculture, Cairo University, Giza, Egypt. $B$. cristata was maintained on malva leaves upside down on moisten cotton pads in fiber-dishes $(20 \mathrm{~cm}$ in diameter) at $25 \pm 1{ }^{\circ} \mathrm{C}$. The cotton pads were moistened daily and all the ends of the leaves were covered with wet cotton to avoid disc dryness and to prevent mite escape. Mites were transferred on fresh malva leaves every 3 days. Newly deposited eggs were singly transferred using a fine brush to the aforementioned prepared leaves.

\section{Entomopathogenic fungi isolates}

Two isolates of entomopathogenic fungi were used in this study. B. bassiana was originally isolated from Aphis gossypii and M. anisopliae from soil at Giza Governorate , Egypt. The fungus was grown on autoclaved Sabourad dexstrose yeast agar (SDAY), containing $1 \%$ peptone, $0.2 \%$ yeast extract, $4 \%$ dextrose and $1.5 \%$ agar dissiloved in $1 \mathrm{~L}$ distilled water and incubated for two weeks at $25 \pm 1{ }^{\circ} \mathrm{C}$ (Nada 2006).

\section{Bioassay procedure}

Spores were harvested by rinsing with sterilized aqueous solution of $0.02 \%$ Tween 80 , then filtered through cheesecloth to reduce mycelium clumping. The spores were counted in the suspension using a haemocytometer (Neubauer Improved HBG, Germany $0.100 \mathrm{~mm} \times 0.0025 \mathrm{~mm}^{2}$ ). Five concentrations: $10^{6}, 5 \times 10^{6}, 10^{7}, 5 \times 10^{7}$ and $10^{8}$ spores $/ \mathrm{ml}$ of each isolate were prepared. Aqueous solution of $0.02 \%$ Tween 80 was used as control.

Fresh uninfested malva leaves were transferred to the laboratory and cleaned by tab water. Leaf discs $1.5 \mathrm{~cm}$ in diameter were submerged into a suspension of $B$. bassiana and $M$. anisopliae concentrations for 10 second as well as aqueous solution of $0.02 \%$ Tween 80 for control. The leaf discs were left to air dry on tissue paper and then transferred upside down to Petri dishs prepared with moistened cotton pads. Each four discs were placed in one Petri dish. Eight replicates for each treatment were used. Five B. cristata adults were placed on 
each treated leaf disc and kept at $25 \pm 1^{\circ} \mathrm{C}$. The cotton pads were moistened daily and all the ends of the leaf discs were covered with wet cotton to avoid disc dryness and to prevent mite from escaping. The leaf discs were changed by fresh clear ones from time to time when necessary. Percentage mortality was assessed daily from 3 to 6 days after inoculation. All dead mites were removed from the Petri dishes and kept in an incubator and the cadavers showing mycosis were considered to be dead as a result of fungus infection.

\section{Statistical analysis}

The concentration and time mortality responses were subjected to probit analysis (Finney, 1971). Susctiplity index according to the methods described by Khidr et al. (2004) were estimated.

Susceptibility index $=$

$$
\frac{\mathrm{LC}_{25}, \mathrm{LC}_{50} \text { and } \mathrm{LC}_{90} \text { of } M . \text { anisopliae }}{\mathrm{LC}_{25}, \mathrm{LC}_{50} \text { and } \mathrm{LC}_{90} \text { of } B \text {. bassiana }} \times 100
$$

\section{RESULTS AND DISCUSSION}

The efficiency of the two isolated entomopathogenic fungi, $B$. bassiana and $M$. anisopliae against adult $B$. cristata was presented in Tables $(1 \& 2)$. The obtained results revealed that the mite was highly susceptible to both $B$. bassiana and $M$. anisopliae. Fungi sporulated outside the body of mites. This mite entered the state of moribund two days after treatment in the high concentrations (i.e. $5 \times 10^{7}$ and $10^{8}$ spores $/ \mathrm{ml}$ ). The fungal sporulation was observed over the surface of the cadaver 4-5 days after treatment Fig (1). Alves et al, (2005) reported that $B$. bassiana was considered a pathogen of citrus rust mite Phyllocoptruta oleivora (Ashmead). Spores of B. bassiana were found to adhere all over the mite body surface, especially at the anal region, where vegetative mycelium was found entering the mite body. The formation of small crystals was noticed inside the mite bodies that were produced during colonization on the mite body cavity by the fungus.

\section{Efficiency based on slope and $\mathrm{LC}_{25}, \mathrm{LC}_{50}$ and $\mathrm{LC}_{90}$ values}

Results of the slope, $\mathrm{LC}_{25}, \mathrm{LC}_{50}$ and $\mathrm{LC}_{90}$ values represented in Table (1) proved that $M$. anisopliae had higher activity against $B$. cristata adults than $B$. bassiana. The correspondent $\mathrm{LC}_{25}$, $\mathrm{LC}_{50}$ and $\mathrm{LC}_{90}$ were $2.31 \times 10^{5}, 1.82 \times 10^{6}$ and $8.8 \times 10^{7}$ spores $/ \mathrm{ml}$, respectively for $M$. anisopliae and $3.74 \times 10^{6}, 2.98 \times 10^{6}$ and $1.6 \times 10^{8}$ spores $/ \mathrm{ml}$ for $B$. bassiana, respectively. Based on the slope values, the slope of $M$. anisopliae was steeper than that of $B$. bassiana (i.e. 0.77 and 2.7, respectively).

\section{Efficiency based on slope and $\mathrm{LT}_{25}, \mathrm{LT}_{50}$ and $\mathbf{L} \mathbf{T}_{90}$ values}

The data reported in Table ( 2 ) showed that $B$. cristata adult treated with $M$. anisopliae had higher susceptibility as well as a rapid mortality at concentration of $10^{8}$ spores $/ \mathrm{ml}$. The $\mathrm{LT}_{25}$, $\mathrm{LT}_{50}$ and $\mathrm{LT}_{90}$ were $1.34,2.2$ and 5.85 days, respectively. $B$. bassiana corresponding values were $3.18,4.08$ and 6.6 days respectively. Based on the slope values, the slope of $M$. anisopliae was steeper than that of $B$. bassiana (i.e. 3 and 6 , respectively).

Susceptibility index was used to find out the relative of susceptibility of $B$. cristata adults to tested entomopathogenic fungi isolates.

Results summarized in Tables (1\&2) showed that the susceptibility index of $B$. bassiana based on the $\mathrm{LC}_{25}, \mathrm{LC}_{50}$ and $\mathrm{LC}_{90}$ were $61.75,61.07$ and $55 \%$, respectively as effective as $M$. anisopliae against $B$. cristata adults. On the other hand efficacy time of $B$. bassiana at $\mathrm{LT}_{25}, \mathrm{LT}_{50}$ and $\mathrm{LT}_{90}$ were $50,53.92$ and $88.64 \%$, respectively as effective as the effectiveness of $M$. anisopliae against $B$. cristata adults.

Table (1) Estimated LC values and susceptibility index for the effect of Metarhizium anisopliae and Beauveria bassiana against, Bryobia cristata

\begin{tabular}{|c|c|c|c|c|c|c|c|}
\hline & \multirow{2}{*}{ slope } & \multirow{2}{*}{$\mathrm{LC}_{25}$} & \multirow{2}{*}{$\mathrm{LC}_{50}$} & \multirow{2}{*}{$\mathrm{LC}_{90}$} & \multicolumn{3}{|c|}{ Susceptibility index relative to } \\
\hline & & & & & $\mathrm{LC}_{25}$ & $\mathrm{LC}_{50}$ & $\overline{L C_{90}}$ \\
\hline M. anisopliae & 0.77 & $2.31 \times 10^{5}$ & $1.82 \times 10^{6}$ & $8.8 \times 10^{7}$ & 100 & 100 & 100 \\
\hline B. bassiana. & 2.7 & $3.74 \times 10^{5}$ & $2.98 \times 10^{6}$ & $1.6 \times 10^{8}$ & 61.76 & 61.07 & 55 \\
\hline
\end{tabular}

Table (2) Estimated LT values and susceptibility index for the effect of Metarhizium anisopliae and Beauveria bassiana against, Bryobia cristata at $10^{8}$ spores $/ \mathrm{ml}$

\begin{tabular}{cccccccc}
\hline & \multirow{2}{*}{ slope } & \multirow{2}{*}{$\mathrm{LT}_{25}$} & \multirow{2}{*}{$\mathrm{LT}_{50}$} & $\mathrm{LT}_{90}$ & \multicolumn{3}{c}{ Susceptibility index relative to } \\
\cline { 7 - 9 } \cline { 6 - 8 } & & & & $\mathrm{LT}_{25}$ & $\mathrm{LT}_{50}$ & $\mathrm{LT}_{90}$ \\
\hline M. anisopliae & 3 & 1.34 & 2.2 & 5.85 & 100 & 100 & 100 \\
\hline B. bassiana. & 6 & 3.18 & 4.08 & 6.6 & 50 & 53.92 & 88.64 \\
\hline
\end{tabular}



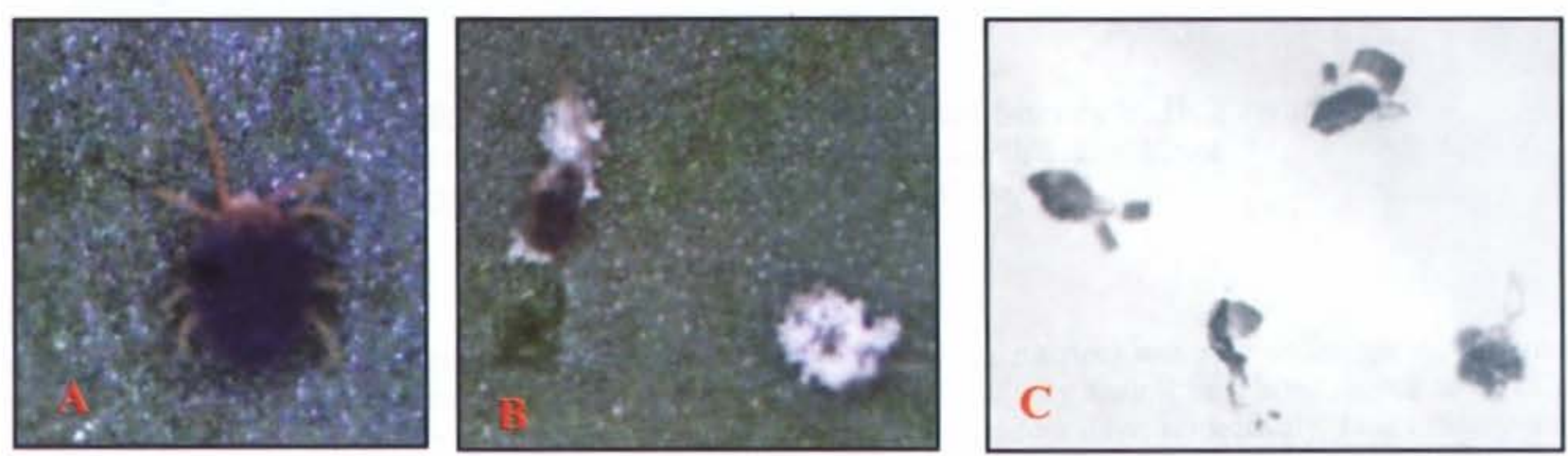

Fig. (1): (A) Healthy adult, B. cristata -(B) Sporulation cadavers infected with B. bassiana showing white mycelial growth- (C) Sporulation cadavers infected by $M$. anisopliae showing laterally adherent conidia chains .

B. bassiana and $M$. anisopliae had high pathogenic activity against Tetranychus urticae (Koch) (Hassan 2008). Similar susceptibility of the broad mite Polyphagotarsonemus latus Bank to the isolated entomopathogenic fungi Paecilomyces fumosoroseus, B. bassiana and M. anisopliae was obtained by Nugroho and Ibrahim 2004. Our results represent the first report on the pathogenic effect of the two entomopathogenic fungi $M$. anisopliae and $B$. bassiana against $B$. cristata adults.

\section{REFERENCES}

Alves, S.B.; Tamai, M. A.; Rossi, L. S. and Castiglioni, E. 2005. Beauveria bassiana pathogenicity to the citrus rust mite Phyllocoptruta oleivora. Exp. Appl. Acarol. 37: 117-122.

Finney, D. J. 1971. Probit analysis. A statistical treatment of the sigmoid response curve. $7^{\text {th }} \mathrm{Ed}$. Cambridge Univ. Press, 333 pp.

Hassan, D. M. A. 2008. Using a biological control method for controlling red spider mite in Egypt. M.Sc. Thesis, Institute of African Research and Studies, Department of Natural Resources, Cairo Univ., 110 pp.

Hughes, W.O.H.; Petersen, K.S.; Ugelvig, L.V.; Pedersen, D.; Thomsen, L.; Poulsen, M. and Boomsma, J. J. 2004. Density-dependence and within-host competition in a semelparous parasite of leaf cutting ants. Bio. Med. Central Evolutionary Biology: 4-45.

Khider, A. A.; Abdeen, S. A.; Hassan, A. I.; AbdelHalim, A. and Mostafa, A. M. 2004. Evaluation of some insecticides and their joint action against the American bollworm, Helicoverpa armigera (Hübner) on lettuce vegetable, Lactuca sativa L. Egypt. J. Appl. Sci., 19 (1), 275-283.

Nada, Maha S. 2006. Sucking insects infesting some crops and their controlling with entomopathogenic fungi in North Africa. Ph. D. Thesis, Institute of African Research and Studies Department of Natural Resources, Cairo Univ., $146 \mathrm{pp}$.

Nugroho, I. and Bin Ibrahim, Y. 2004. Laboratory bioassay of some entomopathogenic fungi against broad mite (Polyphagotarsonemus latus Bank). Int. J. Agric. \& Biol., 6 (2): 223-225.

Vandenburg, J. D., Ramos, M. and Altre, J. A. 1998. Dose-response, age and temperaturerelated susceptibility of the diamondback moth (Lepidoptera: Plutellidae) to two isolates of Beauveria bassiana (Hyphomycetes: Moniliaceae). Envirom. Entomol., 27, 1017-1021.

Zaher, M. A. 1984. Survey and ecological studies on phytophagous, predaceous and soil mites in Egypt, I. Phytophagous mites in Egypt (Nile valley and delta). PL. 480 programm U.S.A. Project No. EG -ARS-30. Grant No. FG- EC139. 228pp. 